Article

\title{
Simulation of Mining-Induced Ground Damage Using Orthogonal Experiments to Determine Key Parameters of Super-Large Coalface: A Case Study in Shendong Coalfield in China
}

\author{
Yinfei Cai ${ }^{1, *}$,, Xiaojing $\mathrm{Li}^{2}$, Wu Xiao ${ }^{3, *}$ and Wenkai Zhang ${ }^{4}$ \\ 1 College of Mining Engineering, Taiyuan University of Technology, Taiyuan 030024, China \\ 2 School of Public Administration, Shanxi University of Finance and Economics, Taiyuan 030024, China; \\ 13810858400@163.com \\ 3 School of Public Affairs, Zhejiang University, Hangzhou 310058, China \\ 4 Institute of land reclamation and ecological restoration, China University of Mining \& Technology (Beijing), \\ Beijing 100083, China; zwk1619@163.com \\ * Correspondence: caiyinfei@tyut.edu.cn (Y.C.); xiaowu@zju.edu.cn (W.X.)
}

Received: 29 February 2020; Accepted: 23 March 2020; Published: 26 March 2020

check for updates

\begin{abstract}
High-strength mining of super-large coalfaces in the Shendong coalfield causes significant damage to the ground surface. To study the key parameters of undermined coalfaces that affect ground damage, 25 numerical simulation models were designed using an orthogonal experimental method based on the geological and mining conditions of the Bulianta Mine. In the orthogonal design, four factors (the lengths in both the dip and strike directions, the thickness and the mining speed of the coalface) were considered, with five levels designed for each factor. The subsidence displacements and deformations caused by the excavation were then simulated and verified using field surveying data. A damage extent index (DEI) was introduced and used to assess the extent of global ground damage caused by each simulative excavation. Analysis of variance (ANOVA) method was then employed to determine the key parameters of the coalface that significantly influence the ground damage. It was found that the coalface dip length and thickness and the coalface thickness can be regarded as the key parameters for ground objects of building and timberland, respectively. This research provides theoretical and technical support for the coordinated exploitation of resources and environments in Shendong and other similar, ecologically fragile coalfields.
\end{abstract}

Keywords: key parameters of a super-large coalface; mining subsidence; global ground damage extent index (DEI); orthogonal experiment; variance analysis

\section{Introduction}

The Shendong coalfield covers the southern part of Erdos City in Inner Mongolia Province, the northern part of Yulin City in Shaanxi Province and Baode County in Shanxi Province. This mining field is approximately $12,860 \mathrm{~km}^{2}$ with an overall production capacity of more than 200 million tons, which was $67.7 \%$ of the national production in 2011 [1]. There are several large modern coal mines in this coalfield, including Bulianta Mine, Daliuta Mine and Bu'ertai Mine, with capacities of more than 20 million tons each; there are approximately a dozen other mines in the region with capacities that are more than 10 million tons each. The geological conditions of the coal seams in this region are characterized as being shallow, thick and horizontal [1,2], which implies super-large coalfaces that can be mined with high-strength approaches. The definition of "super-large" is not strict, according to 
Refs. [1-8], as a super-large coalface should at least have a length in the dip direction of $300 \mathrm{~m}$, a length in the strike direction of $3000 \mathrm{~m}$, a mining thickness of $5 \mathrm{~m}$ and a mining speed of $8 \mathrm{~m} /$ day.

As the Shendong coalfield is a very important coal-producing region in China, the subsidence characteristics and the damages on the ground environment are both of high concern.

Mining subsidence is a damage phenomenon that is induced from the exploitation of underground ore bodies. After excavation, the overlying strata first fractures and bends. By employing field data and physical and numerical experiments, the fracture theories and control methods of the overlying strata have been studied in the Shendong coalfield $[6,9,10]$.

The subsidence phenomenon then develops from overlying strata to the ground surface. Observation stations are often used and reliable method to monitor ground subsidence. By the end of 2013, there were 17 coalfaces in 10 mines that were being monitored in the Shendong coalfield [5]. Other modern monitoring technologies, such as interferometric synthetic aperture radar (InSAR) [11,12], have also been employed to obtain subsidence data. However, due to noise and other factors, InSAR monitoring results cannot easily reflect actual subsidence deformations of slopes and curvatures [12]. Numerical [13-15] and physical [6,8] simulations are also usually used in ground subsidence research in this coalfield. Using all these aforementioned methods, the ground subsidence characteristics and subsidence parameters $[13,16]$ as well as their dynamics [11] have been studied. The super-large size of the coalface and high-strength mining cause the active period of the subsidence process to be short with the main subsidence values concentrated during this period [5]. Ground fissures are readily developed, and occasional discontinuous subsidence phenomena occur at the surface [8,17-19]. Furthermore, some improved computation methods have been developed to better fit the ground subsidence for this coalfield, such as a prediction method based on the boundary value method [20], which can be used to more accurately compute the vertical subsidence on the ground.

The ground environment is unavoidably influenced or damaged by the mining subsidence. In this region, the vegetation, crops, underground water, buildings, biodiversity and other ecological features are the primary concerned ground objects [4,21-24]. Due to the high-strength mining and the fact that the Shendong coalfield is a fragile-ecology region [25], the damage extent of the ground environment can be commonly considered to be serious [26]. However, it is fortunate that super-large coalfaces induce damage that has a certain "self-repairing" characteristic and damage mitigation ability $[4,27]$. The existing assessment criteria of ground damage are not uniform [7,28]. For example, the vertical subsidence, slope and horizontal deformation have been considered as the sensitive evaluation factors for ground damage [28]; and more complex criteria have also been used, such as a criterion with 11 indexes that include organic material, vegetation coverage, an additional mining-induced slope, etc. [7]. To repair these subsided lands, some reclamation methods have been performed and achieved good results $[22,26,29]$.

In the mining area, the building is one of the concerned and well-studied ground objects. Its damage assessment methods are classified into three types [30,31], including empirical, analytical and numerical methods. The empirical method employs mining subsidence values to assess the building damage extent [32-34]. It is simple but can only achieve a rough estimate for each single building. The numerical method uses numerical simulation software (based on the finite element method $[35,36]$ or the distinct element method [37]) to study the damages of individual structures. It can provide detailed mechanical analyses but is time-consuming. The analytical method mainly uses beam systems to model the buildings and then computes the stress and strain within the buildings [38-40]. Its complexity of the modeling and computation and accuracy of the result are between the aforementioned two methods. Given that the building (also the other ground objects) damage assessment is an intermediary of this study, we do not intend to improve its precision or expand its applicability. Therefore, the empirical method will be employed in this study, as it is simple and has available industry standards.

In practice, coal mine companies are more concerned about their profits and prefer to implement land reclamation or provide pecuniary reparation for the mining-damaged land or surface attachments (e.g., buildings). Protective exploitation is not normally under consideration unless there are important 
surface objects. The present research [41-44] on land reclamation in the mining area is mainly concentrated on the stage of post-mining. It is not an optimal solution for environment protection, as the damaged environment needs a long time and sometimes is difficult to be recovered. Therefore, reducing the damage extent of the ground surface by optimizing the mining design before excavation is worth studying. At least, it can become a choice when the mining area environment is increasingly concerned.

This research aims to identify the key parameters of super-large coalfaces as related to the damage extent of the ground surface. Then these key parameters can be used to optimize the coalface design before underground exploitation to reduce the ground damage. The research process can be mainly divided into three steps:

(1) Subsidence Simulation

Considering only field surveying data is insufficient to study the influence of subsidence on the damage. In addition, the permutations and combinations of the coalface parameters are too vast to be accounted for in computer simulations. Therefore, the orthogonal design method is employed to design a series of simulation models to study such ground damage.

(2) Damage Assessment

As the existing ground damage assessment criteria are non-uniform, sometimes complex and aiming at a single ground point, a new damage extent index (DEI) is introduced in this paper. It has the characteristics as follows: (i) can be used to represent the global damage extent of the entire subsidence range; (ii) based on the damage grading of the ground points, which can be assessed by the existing criteria; (iii) quantitative and can be employed to build relationships with the coalface parameters.

(3) Key Parameter Determination

The analysis of variance (ANOVA) method is used to determine the key parameters of the coalface whose variations significantly influence the DEI.

The workflow of this study is shown as in Figure 1.

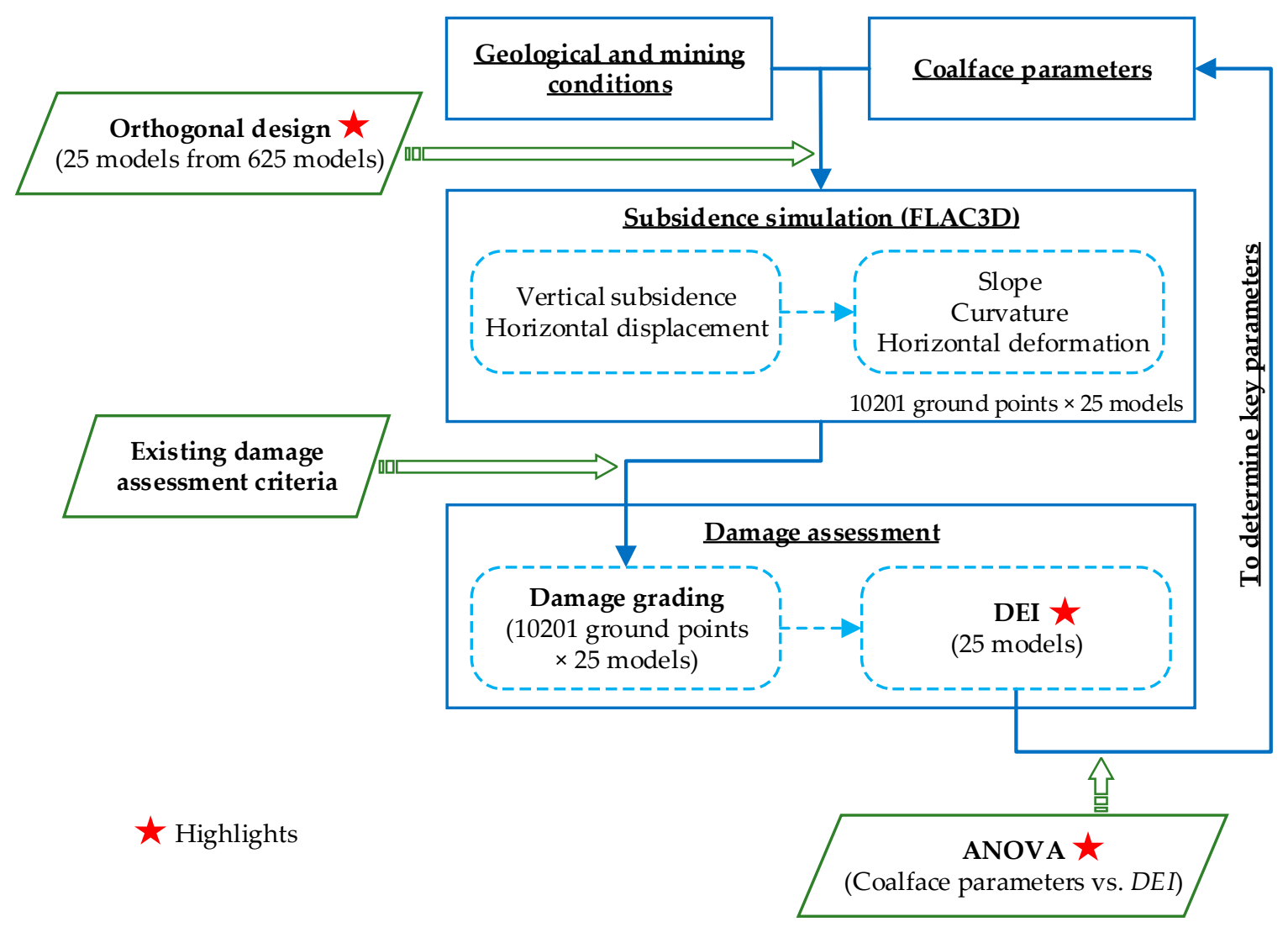

Figure 1. Flow diagram of this study. 


\section{The Prototypical Coalface}

The prototype coalface for this research is located in Bulianta Mine, with a length in the dip direction of $300.5 \mathrm{~m}$, a length in the strike direction of $3592 \mathrm{~m}$, a mean thickness of $4.81 \mathrm{~m}$, a dip angle of $1-3^{\circ}$ and a mean mining depth of $200 \mathrm{~m}$. From the bottom to the top, the overlying strata of the coal seam consist of three layers, including the false roof layer composed primarily of siltstone, the bedrock layer composed primarily of siltstone and sandy mudstone; the Quaternary layer composed of loose soil, whose mean thicknesses are 4.98, 181.6 and 3-30 m, respectively. This coalface was excavated using a fully mechanized mining method with a mean mining speed of $12 \mathrm{~m} /$ day; its roof management is the caving method. The vertical subsidence of the ground surface of this coalface has been surveyed 11 times. Based on the field surveying data, the vertical subsidence coefficient is 0.55 ; the strike boundary angle is $35^{\circ}$ [25].

\section{Design and Computation of Orthogonal Simulation Experiment}

The FLAC ${ }^{3 \mathrm{D}}$ (Itasca Consulting Group, Inc., Minneapolis, MN, USA) is a numerical simulation software based on the finite difference principle and is used to simulate the mining subsidence and surface damage caused by the super-large coalface under the geological and mining conditions of Bulianta Mine.

The orthogonal design method was considered in the design of experiment scheme to reduce the quantity of the FLAC ${ }^{3 D}$ models. This approach is good at studying problems with multiple factors and multiple levels [10]. It selects some typical tests from the complete experimental scheme based on orthogonality. These selected tests should be dispersed and comparable. In our simulation cases, four coalface parameters were considered, with five different values for each. On the basis of the permutations and combinations, a total of $5^{4}=625$ models were demanded for the complete experiment scheme; by contrast, only a total of 25 models are required by the orthogonal design. The experimental efficiency was greatly improved by the latter.

\subsection{Mathematical Model in FLAC $3 D$}

In our simulations, the pre-defined mathematical models in the software of FLAC ${ }^{3 \mathrm{D}}$ were employed without modification. These models are briefly described as follows (mainly from "FLAC ${ }^{3 D}$ user's guide") and can be regarded as the foundation of our tests.

There are some conventions that should be noted first: in the Lagrangian formulation adopted in the FLAC ${ }^{3 \mathrm{D}}$, a point in the medium is characterized by the vector components $\boldsymbol{x}_{i}, \boldsymbol{u}_{i}, \boldsymbol{v}_{i}$ and $d \boldsymbol{v}_{i} / d t(i=1$, 3 ) of position, displacement, velocity and acceleration, respectively; the symbol $\boldsymbol{a}_{i}$ denotes component $i$ of the vector $\boldsymbol{a}$ in a Cartesian system of reference axes; $\boldsymbol{a}_{i j}$ is component $(i, j)$ of tensor $\boldsymbol{a}$; and $\boldsymbol{a}_{, i}$ is the partial derivative of $\boldsymbol{a}$. A bold letter designates a vector or a tensor, similarly hereinafter.

(1) Stress

The stress state at a point of the medium is characterized by the symmetric stress tensor $\sigma_{i j}$. The traction vector $\boldsymbol{t}$ on a face with unit normal $n$ is given by Cauchy's formulae:

$$
\boldsymbol{t}_{i}=\sigma_{i j} n_{i}
$$

(2) Rate of Strain and Rate of Rotation

If the particles of the medium move with velocity $v$, the medium experiences an infinitesimal strain determined by the translations $v_{i} d t$ in an infinitesimal time $d t$ and the corresponding components of the strain-rate tensor are:

$$
\xi_{i j}=\frac{1}{2}\left(v_{i, j}+v_{j, i}\right)
$$

The components of the rotation-rate tensor are:

$$
\omega_{i j}=\frac{1}{2}\left(v_{i, j}-v_{j, i}\right)
$$


(3) Equations of Motion and Equilibrium

Application of the continuum form of the momentum principle yields Cauchy's equations of motion:

$$
\sigma_{i j, j}+\rho \boldsymbol{b}_{i}=\rho \frac{d v_{i}}{d t}
$$

where $\rho$ is the mass per unit volume of the medium and $\boldsymbol{b}$ is the body force per unit mass.

In the case of static equilibrium of the medium, the acceleration $d v / d t$ is zero. Then, the above equation reduces to the partial differential equations of equilibrium:

$$
\sigma_{i j, j}+\rho \boldsymbol{b}_{i}=0
$$

(4) Constitutive Model

In excavation studies, the Mohr-Coulomb yield criterion is usually employed [45-47]:

$$
f^{\prime}=\sigma_{\max }-\sigma_{\min } \frac{1+\sin \varphi}{1-\sin \varphi}+2 c \sqrt{\frac{1+\sin \varphi}{1-\sin \varphi}}
$$

where $f^{\prime}$ is the shear yield function; $\sigma_{\max }$ and $\sigma_{\min }$ are the maximum and minimum principal stresses, respectively; $\varphi$ is the internal friction angle; and $c$ is the cohesion.

\subsection{Design of Orthogonal Experiment Scheme}

The high-strength mining of a super-large working face means that the mining size is large, and the mining speed is fast. The parameters of the coalface itself were concerned in this study; the mechanical properties and dimensions of the surrounding rocks were fixed. Therefore, the experimental factors (i.e., coalface parameters) were determined as follows:

(1) The length in the dip direction of the coal seam

(2) The length in the strike direction of the coal seam

(3) The thickness of the coal seam

(4) The mining speed

Since the local coal seam is nearly horizontal, the dip angle of the coalface was not considered and was set to zero in all models.

For each experimental factor, five levels (i.e., factor values) were designed; their mean values were close to the actual values of the prototype coalface. Specially, the factor of the length in the dip direction (3592 $\mathrm{m}$ for the prototype) was designed to be from 600-1000 $\mathrm{m}$ to decrease the model size. As the mining depth was around $200 \mathrm{~m}$, the designed dip length values still ensured that the excavations were critical (or super-critical), where "critical excavation" is a mining state with respect to the size of the excavation zone. When an excavated zone is sufficiently large, so the induced maximum vertical subsidence just reaches its theoretical extreme value under a given mining condition, the excavation is considered to be critical. When an excavated zone is smaller than this size, the maximum vertical subsidence is lower than the theoretical value, which is the state called sub-critical. Conversely, the super-critical state is where the maximum vertical subsidence does not enlarge while the mining zone is developing, which creates a flat bottom around the center of the excavated zone.

The specific factors and levels of the orthogonal experiment are shown in Table 1. 
Table 1. Selection of factors and levels for the orthogonal experiment.

\begin{tabular}{ccccc}
\hline & \multicolumn{4}{c}{ Experiment Factors (Parameters of the Coalface) } \\
\cline { 2 - 5 } Levels & $\begin{array}{c}\text { Factor A } \\
\text { Length in Dip } \\
\text { Direction (m) }\end{array}$ & $\begin{array}{c}\text { Factor B } \\
\text { Length in Strike } \\
\text { Direction (m) }\end{array}$ & $\begin{array}{c}\text { Factor C } \\
\text { Thickness (m) }\end{array}$ & $\begin{array}{c}\text { Factor D } \\
\text { Mining Speed } \\
\text { (m/day) }\end{array}$ \\
\hline Level 1 & 250 & 600 & 2 & 8 \\
Level 2 & 300 & 700 & 4 & 10 \\
Level 3 & 350 & 800 & 6 & 12 \\
Level 4 & 400 & 900 & 8 & 14 \\
Level 5 & 450 & 1000 & 10 & 16 \\
\hline
\end{tabular}

All the designed tests are shown in Table 2 and were based on the orthogonal design principle that considers the selected four factors and five levels. Thus, a total of 25 simulation tests were performed. Compared with the complete experiment scheme, which required a total of $5^{4}=625$ models, the orthogonal design method greatly reduced the complexity of the research.

Table 2. Orthogonal experimental scheme.

\begin{tabular}{|c|c|c|c|c|}
\hline \multirow[b]{2}{*}{ Test ID } & \multicolumn{4}{|c|}{ Experiment Factors (Parameters of The Coalface) } \\
\hline & $\begin{array}{c}\text { Factor A } \\
\text { Length in Dip } \\
\text { Direction (m) }\end{array}$ & $\begin{array}{c}\text { Factor B } \\
\text { Length in Strike } \\
\text { Direction (m) }\end{array}$ & $\begin{array}{c}\text { Factor C } \\
\text { Thickness (m) }\end{array}$ & $\begin{array}{c}\text { Factor D } \\
\text { Mining Speed } \\
\text { (m/day) }\end{array}$ \\
\hline 1 & 400 & 700 & 10 & 8 \\
\hline 2 & 400 & 800 & 6 & 10 \\
\hline 3 & 300 & 600 & 6 & 14 \\
\hline 4 & 250 & 1000 & 6 & 16 \\
\hline 5 & 300 & 1000 & 10 & 12 \\
\hline 6 & 400 & 600 & 4 & 16 \\
\hline 7 & 300 & 800 & 8 & 8 \\
\hline 8 & 300 & 900 & 4 & 10 \\
\hline 9 & 350 & 700 & 6 & 12 \\
\hline 10 & 350 & 900 & 8 & 16 \\
\hline 11 & 450 & 900 & 6 & 8 \\
\hline 12 & 350 & 800 & 2 & 14 \\
\hline 13 & 300 & 700 & 2 & 16 \\
\hline 14 & 250 & 800 & 4 & 12 \\
\hline 15 & 400 & 1000 & 8 & 14 \\
\hline 16 & 250 & 600 & 2 & 8 \\
\hline 17 & 450 & 800 & 10 & 16 \\
\hline 18 & 450 & 600 & 8 & 12 \\
\hline 19 & 350 & 600 & 10 & 10 \\
\hline 20 & 350 & 1000 & 4 & 8 \\
\hline 21 & 450 & 1000 & 2 & 10 \\
\hline 22 & 250 & 900 & 10 & 14 \\
\hline 23 & 450 & 700 & 4 & 14 \\
\hline 24 & 400 & 900 & 2 & 12 \\
\hline 25 & 250 & 700 & 8 & 10 \\
\hline
\end{tabular}

\subsection{Design of Simulation Models}

Based on the in-situ conditions from the Bulianta Mine, all models are divided into five rock layers (including the coal seam) and defined using the Mohr-Coulomb constitutive model in the software of FLAC ${ }^{3 \mathrm{D}}$. The layer thicknesses and the physical and mechanical properties are shown in Table 3. The purpose of this research is to identify the key parameters of the coalface that affect the ground damage. Therefore, these strata conditions should be fixed for all designed simulation models, except the thickness of the coal seam, which is one of the objects of interest. 
For each model, the horizontal displacement at the four vertical boundaries is restricted. More specifically, as shown in Figure 2, the x-direction displacement in right and left side planes is fixed, as well as the y-direction displacement in front and back side planes. The vertical displacement at the bottom is also restricted, whereas the top surface is free.

All internal displacements of the model are caused by gravity without any additional external forces. That is, the initial stress of the model only depends on the weight and property of the layers.

Table 3. The rock layers and their thickness and physical and mechanical characteristics in the simulation models.

\begin{tabular}{cccccccc}
\hline Layers & $\begin{array}{c}\text { Thickness } \\
(\mathbf{m})\end{array}$ & $\begin{array}{c}\text { Density } \\
\left.\mathbf{( K g} \cdot \mathbf{m}^{-3}\right)\end{array}$ & $\begin{array}{c}\text { Young's } \\
\text { Modulus (GPa) }\end{array}$ & $\begin{array}{c}\text { Poisson's } \\
\text { Ratio }\end{array}$ & $\begin{array}{c}\text { Cohesion } \\
\mathbf{( M P a )}\end{array}$ & $\begin{array}{c}\text { Tension } \\
\mathbf{( M P a )}\end{array}$ & $\begin{array}{c}\text { Friction } \\
\text { Angle }\left(^{\circ}\right)\end{array}$ \\
\hline Soil layer & 17 & 1700 & 12 & 0.3 & 0.02 & 12 & 20 \\
Rock layer & 180 & 2410 & 21.25 & 0.245 & 1.7 & 21.85 & 32 \\
Roof & 5 & 2410 & 24.5 & 0.24 & 1.8 & 26.5 & 32 \\
Coal Seam & $*$ & 1320 & 13 & 0.26 & 1 & 13.5 & 30 \\
Floor & 100 & 2410 & 24.5 & 0.24 & 1.8 & 26.5 & 32 \\
\hline
\end{tabular}

Note *: the thickness of the coal seam is defined in Table 2 and varying for different tests.

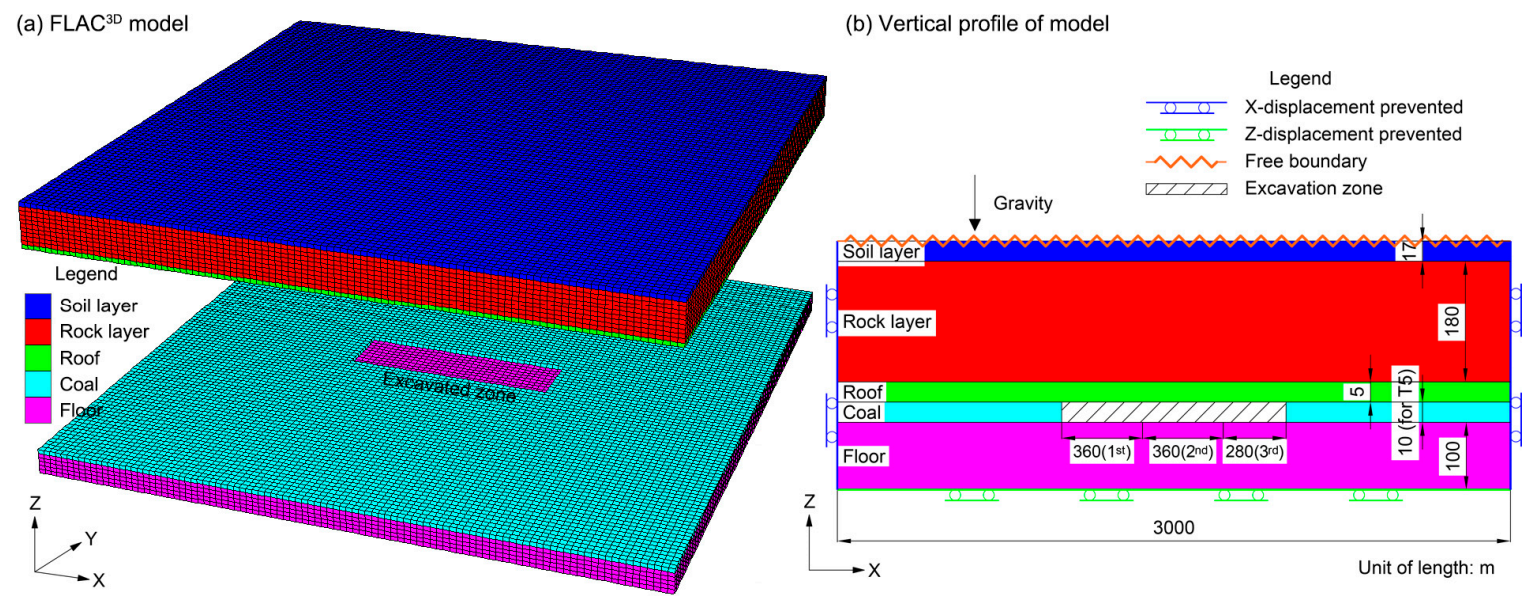

Figure 2. Model of Test 5 after excavation: (a) FLAC ${ }^{3 \mathrm{D}}$ simulation model (overlying layers are elevated for illustration); (b) vertical profile of model with dimensioning and boundary conditions.

The model after excavation for Test 5 is shown in Figure 2 as an example. To better illustrate the ore body layer, for the 3D model in Figure 2a, the overlying strata are uniformly raised by $1000 \mathrm{~m}$ (just for display). The plane size of this model is $3000 \times 3000 \mathrm{~m}$, which is fixed for all 25 models. The coal thickness is $10 \mathrm{~m}$ for this test (from Table 2), while the thicknesses of the other layers are shown in Table 3. This model (before excavation) has a total of 183,618 nodes and 170,000 blocks.

After the initial model balance, the displacements and velocities are reset to zero. The simulative excavation in the coal layer is then implemented based on the orthogonal experiment scheme given in Table 2. The excavation zone for Test 5 is $300 \times 1000 \mathrm{~m}$. It is noted that to consider the mining speed, the excavation zone is extracted several times to match the designed size. Each time, the excavated length in the strike direction is set as the designed mining speed times 30 days (e.g., $12 \mathrm{~m} /$ day $\times 30$ day for Test 5). As illustrated in Figure 2b, to shape the final excavation zone (1000 $\mathrm{m}$ in the x-direction), we mined 3 times in the coal layer: 360, 360 and $280 \mathrm{~m}$ for the first, second and third time, respectively.

\subsection{Simulation of Ground Subsidence Displacements and Deformations}

(1) Computation of Ground Displacements (Vertical Subsidence and Horizontal Displacement) 
The vertical subsidence and horizontal displacement at all model nodes are extracted after the excavations. The ground values (top surface of the model) are managed with the software Mathematica in table form. As shown in Figure 3, the vertical subsidence is plotted as iso-contours and the horizontal displacement is plotted as vectors. The horizontal displacement could also be plotted as iso-contours in the strike and dip directions of the coalface, which would require two separate figures.

The criticality of the excavation is related to the size of the coalface, including the lengths in the dip and strike directions. Based on the experiment design, the minimum length in the strike direction was $600 \mathrm{~m}$ to ensure the excavation was always super-critical along this direction with a mining depth of $200 \mathrm{~m}$. The simulated vertical subsidence data show that when the length in the dip direction is 250, 300, 350, 400 and $450 \mathrm{~m}$, the vertical subsidence coefficients are 0.47, 0.53, 0.56, 0.56 and 0.56, respectively. Therefore, when the length in dip direction reaches $350 \mathrm{~m}$, the excavation is considered to be critical in this direction, giving a vertical subsidence coefficient of 0.56 .

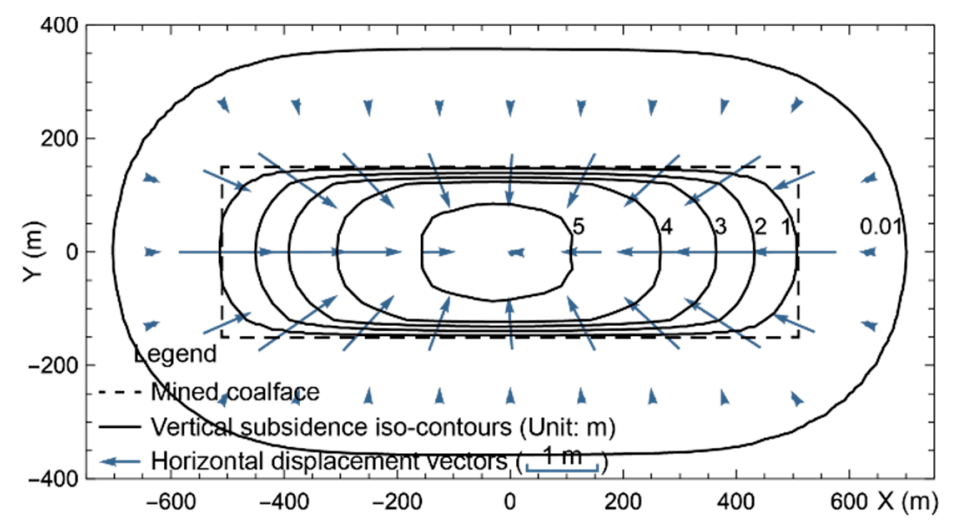

Figure 3. Vertical subsidence iso-contours and horizontal displacement vectors for Test 5.

(2) Computation of Ground Deformations (Slope, Curvature and Horizontal Deformation)

Ground damage is not only determined from the ground displacements, which are the direct result of the simulations, but also by the ground deformations, including the slope, curvature and horizontal deformation. These deformation factors can be derived from the ground displacements.

The slope $i(x)$ is the first derivative of the vertical subsidence $W(x)$ :

$$
i(x)=\frac{d W(x)}{d x}
$$

The curvature $K(x)$ is the first derivative of the slope $i(x)$ (second derivative of the vertical subsidence $W(x))$ :

$$
K(x)=\frac{d i(x)}{d x}=\frac{d^{2} W(x)}{d x^{2}}
$$

The horizontal deformation $\varepsilon(x)$ is the first derivative of the horizontal displacement $U(x)$ :

$$
\varepsilon(x)=\frac{d U(x)}{d x}
$$

These three deformation factors can be represented as two orthogonal components, normally along the strike and dip directions of the coalface. Taking Test 5 as an example, the slope and horizontal deformation are plotted in Figure 4. 

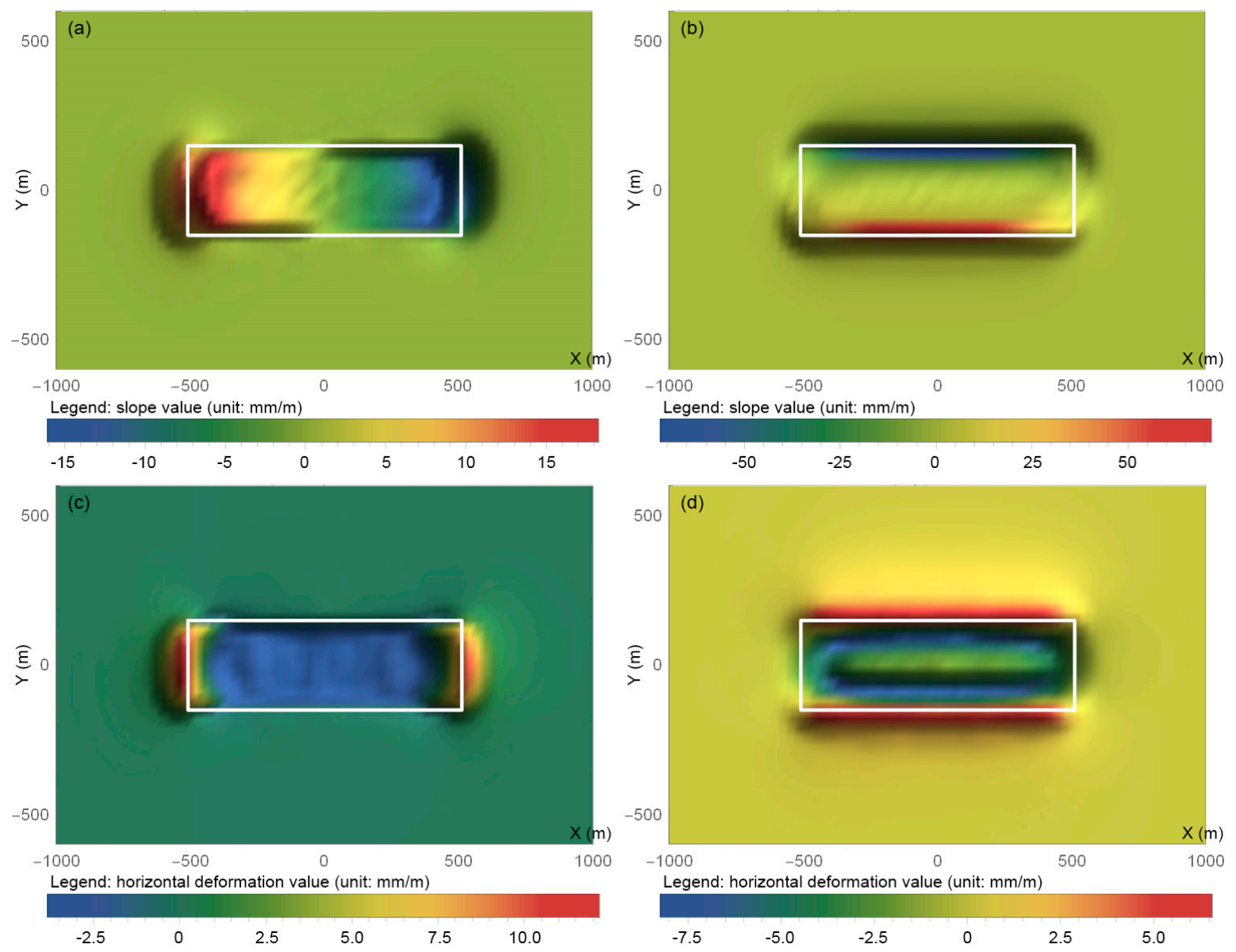

Figure 4. Slope and horizontal deformation for Test 5 (white rectangle is the undermined coalface): (a) slope in the strike direction of the coalface; (b) slope in the dip direction; (c) horizontal deformation in the strike direction; (d) horizontal deformation in the dip direction.

(3) Verification of Simulated Results

The vertical subsidence of the ground surface was measured 11 times during the excavation of the prototype coalface; the 11th dataset (obtained after the subsidence was stopped) was used to verify the corrections in the numerical simulation results. A simulation test with the coalface parameters close to the prototype is employed for the comparisons. Test 3 was appropriate as its length in the dip direction, thickness and mining speed were $300 \mathrm{~m}, 6 \mathrm{~m}$ and $14 \mathrm{~m} /$ day. However, the length in the strike direction of the coalface of Test 3 was $600 \mathrm{~m}$, which was much shorter than that of the prototype (3529 $\mathrm{m}$ ). Such a length ensured that the excavation reached critical and the comparison of the surveying and simulation data was only at the half-side close to the open-off cut. Therefore, differences in the strike lengths are acceptable. For a better comparison, the vertical subsidences of the surveying and simulation data were divided by their mining thicknesses (4.81 and $6 \mathrm{~m}$ ) and then plotted (Figure 5).

The numerical simulation is concerned about some specific geological and mining conditions, so the other conditions were simplified, which makes the simulation model similar, but not identical to the prototype. As a result, the simulated subsidence data did not entirely fit the surveying data $[14,15,48,49]$. Moreover, field measurement precision was dependent on many issues, such as the stability of the measuring points, the quality of the measuring instruments and the observation conditions. Therefore, noise was always a part of field surveying data. In contrast, simulated subsidence results usually appear as a smooth line (or curved surface), as they are produced by indoor computation.

Figure 5 shows that the surveying and simulation data fit well together, especially in the aspects of the trend, border and extreme value. The vertical subsidence coefficients, horizontal displacement 
coefficients and the boundary angles (boundary is where the vertical subsidence is $10 \mathrm{~mm}$ ) in the strike direction as obtained from field surveying and numerical simulations are all close to each other (Table 4). The above comparison illustrates the credibility of the simulations.

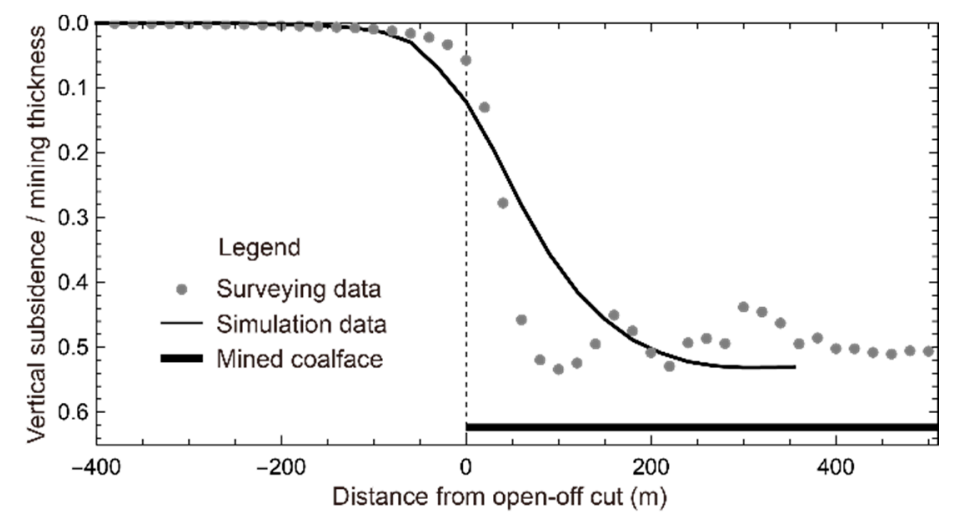

Figure 5. Comparison between the simulated vertical subsidence curve of Test 3 and the 11th field monitoring data of a coalface in Bulianta mine (both along the strike direction).

Table 4. Comparison of the subsidence coefficients obtained from Test 3 and the field monitoring data.

\begin{tabular}{ccc}
\hline Factors & Test 3 & Field Monitoring Data [25] \\
\hline Vertical subsidence coefficient & 0.53 & 0.55 \\
Horizontal displacement coefficient & 0.30 & 0.26 \\
Boundary angle in strike direction & $34.40^{\circ}$ & $35^{\circ}$ \\
\hline
\end{tabular}

\section{Key Parameters of The Coalface on Ground Damage}

The computed subsidence factors-including the displacements (vertical subsidence and horizontal displacement) and deformations (slope, curvature and horizontal deformation) - are used to assess the damage extent of all ground points. Then, the DEI was defined to represent the global damage of the subsidence range and used to analyze the key parameters of the coalface with respect to the ground damage.

\subsection{Grading of Mining-Induced Ground Damage}

When assessing ground damage, it is necessary to consider the objects on the ground surface. Different objects are sensitive to different subsidence factors; their thresholds for damage are distinct. In fact, the damage assessment of the ground is aimed at ground objects and not the ground itself. Thus, the objects should be identified before the assessment.

Two kinds of objects are selected for this study: buildings and timberland. Both objects are typical in our study area and have ready-made and distinct assessment criteria. It is noted that this paper is not concerned with rulemaking, but instead uses existing industry standards. Tables 5 and 6 show the damage assessment criteria of buildings and timberland as derived from "The Regulations of Coal Mining and Pillar Design for Protecting Buildings, Water Bodies, Railways, Main Mineshafts and Tunnels" [33] and "Regulation on Compiling Land Reclamation Plan-Part 3: Underground Coalmine" [50], respectively. From these two assessment criteria, it is found that the building damage is primarily sensitive to the subsidence factors of deformations and the timberland damage is related to both subsidence displacements and deformations. 
Table 5. Grading criteria of building damage induced by mining subsidence [33].

\begin{tabular}{|c|c|c|c|}
\hline \multirow{2}{*}{ Damage Grades } & \multicolumn{3}{|c|}{ Grading Indexes } \\
\hline & Horizontal Deformation $(\mathrm{mm} / \mathrm{m})$ & Slope $(\mathrm{mm} / \mathrm{m})$ & Curvature $(1 / \mathbf{k m})$ \\
\hline 1 & $\leq 2.0$ & $\leq 3.0$ & $\leq 0.2$ \\
\hline 2 & $\leq 4.0$ & $\leq 6.0$ & $\leq 0.4$ \\
\hline 3 & $\leq 6.0$ & $\leq 10.0$ & $\leq 0.6$ \\
\hline 4 & $>6.0$ & $>10.0$ & $>0.6$ \\
\hline
\end{tabular}

Table 6. Grading criteria of timberland damage induced by mining subsidence [50].

\begin{tabular}{cccc}
\hline \multirow{2}{*}{ Damage Grades } & \multicolumn{3}{c}{ Grading Indexes } \\
\cline { 2 - 4 } & Vertical Subsidence $(\mathbf{m})$ & Horizontal Deformation $(\mathbf{m m} / \mathbf{m})$ & Slope $(\mathbf{m m} / \mathbf{m})$ \\
\hline 1 & $\leq 2.0$ & $\leq 8.0$ & $\leq 20.0$ \\
2 & $\leq 5.0$ & $\leq 20.0$ & $\leq 50.0$ \\
3 & $>5.0$ & $>20.0$ & $>50.0$ \\
\hline
\end{tabular}

When assessing ground damage, all the involved subsidence factors at the top nodes of a simulation model should be compared to the criteria in either Table 5 or Table 6. As long as one subsidence factor reaches the lowest value of a damage grade, the damage extent of the ground at and around the node is assessed as being at that damage grade. The damage area at each damage grade can be computed at the same time.

Taking Test 5 as an example, the results of the damage grade assessment regarding buildings and timberland are shown in Figure 6.

From Figure 6a (distribution of the building damage grade), the highest damage grade (grade 4) occurs along the edges of the coalface, and the damage grade appears lower (grades 3 and 2) inside the coalface. This is because only the subsidence deformations (slope, curvature and horizontal deformation) are considered in the building damage assessment criteria. From studies of subsidence rules $[11,48,51]$ and the illustration in Figure 4, the maximum values of the subsidence deformations normally appear along the edges of the mined coalface.

From Figure $6 \mathrm{~b}$ (distribution of the timberland damage grade), the highest damage grade (grade 3) appears both around the center and along the edges of the coalface. This is because both the subsidence deformations (slope and horizontal deformation) and the vertical subsidence are considered in the assessment criteria of timberland; the maximum vertical subsidence appears around the coalface center, while the maximum deformations appear along the coalface edges.

The above analyses are based on the simulation results obtained for Test 5; for the other tests, the absolute damage grades could be different, but the distribution rules for the damage grades are the same. 


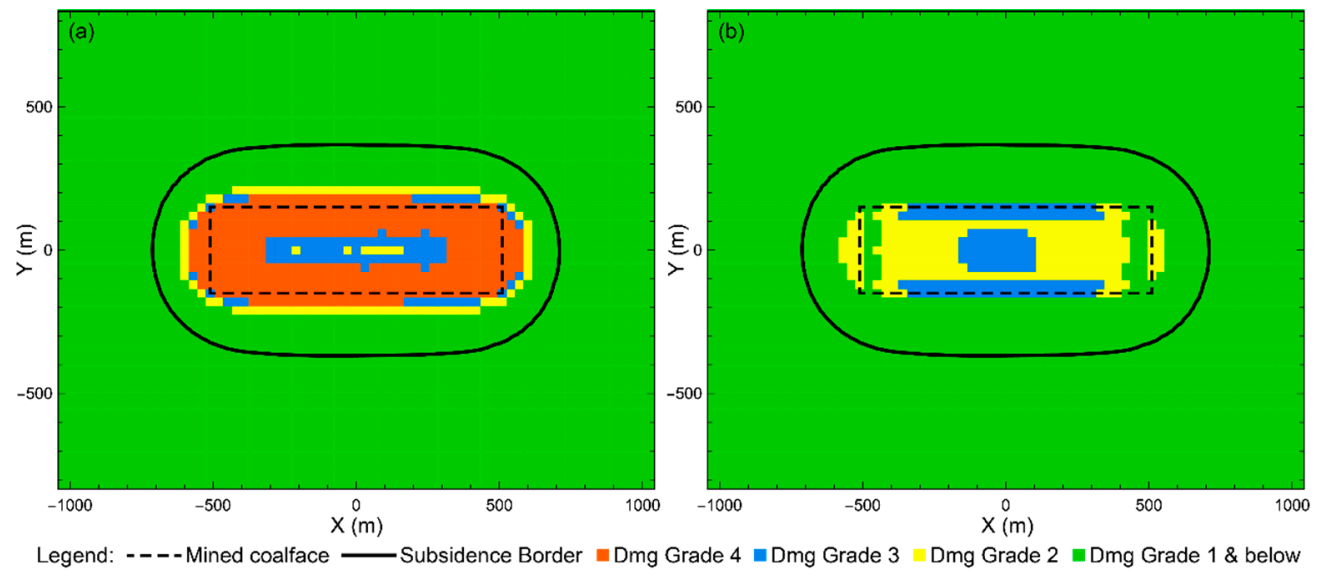

Figure 6. Distribution of ground damage grade for Test 5: based on (a) building damage criteria (Table 5) and (b) timberland damage criteria (Table 6).

According to the subsidence rules, normally, the permanent and dynamic subsidence damages happen along the coalface edges and inside the coalface, respectively. They are both concerned in mining damage studies. In the Shendong coalfield, the dynamic damage inside the coalface appears "self-repairing" characteristic, which can be mainly attributed to the following two reasons:

(1) During the excavation process, the ground surface upon and inside the coalface is first influenced by tensile deformation and then influenced by compressive deformation. The cumulative influence of these two deformations makes the ground damage extent first increases and then decreases.

(2) The topsoil of our study area is aeolian sandy soil, which has properties as easy weathering and high fluidity. According to Refs. $[4,27,52]$, such topsoil is advantageous to the restoration of the mining-damaged environment. For example, as illustrated in Figure 7, the ground fissures are self-restored without human intervention within one month after their first appearance.
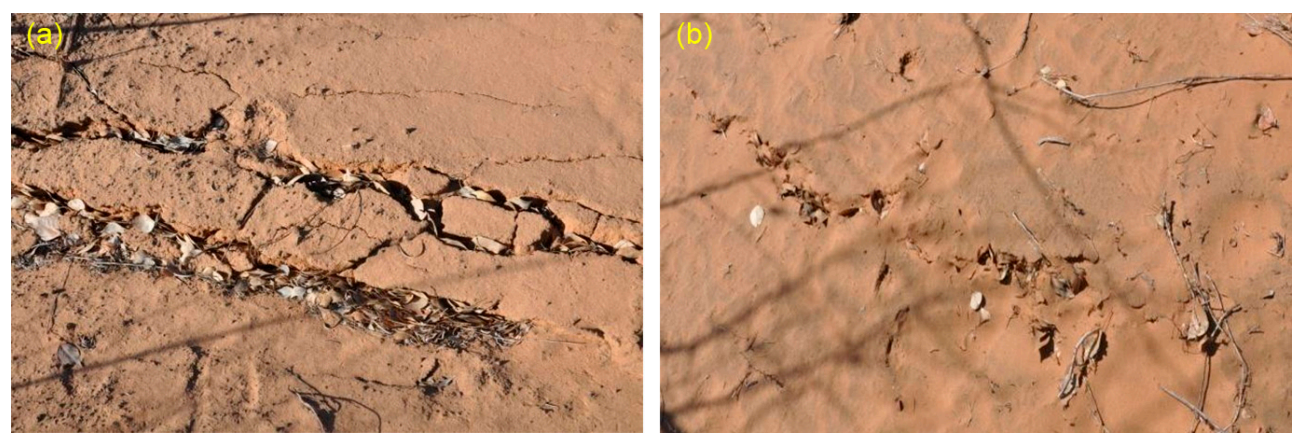

Figure 7. Self-restoration of mining-induced fissures in the Shendong coalfield [52]: (a) the mining-induced ground fissures; (b) the self-restored ground fissures at the same site.

As this study uses existing industry standards, the distribution and extent of the ground damage are very dependent on the involved assessment indicators. If the vertical subsidence is used, the center of the subsided basin is with higher damage grade; otherwise, the lower grade appears around the center.

\subsection{Ground Global Damage Extent Index (DEI)}

The distribution figures of the damage grade can be used to gain intuition and judge the extent of ground damage as induced by the subsidence, but in a more subjective way. The intent is to find a more quantitative index to represent the extent of global damage of the entire subsidence range. 
More specifically, the goal is to use a single index to represent the damage extent caused from a given simulation test and then to study the influence of the coalface parameters on this index.

Both the damage areas and grades are considered to affect the index-DEI, which is defined as the ratio of the summation of all the products of the damage area and the relevant damage grade to the total subsidence area:

$$
D E I=\frac{1}{S_{10}} \sum_{g r d=1}^{n} S_{g r d} \times g r d
$$

where $S_{10}$ is the area of the entire subsidence range (where the vertical subsidence $>10 \mathrm{~mm}$ ), grd is the damage grade valued from 1 to $n$ ( $n=3$ and 4 for timberland and buildings, respectively) and $S_{\text {grd }}$ is the area of the ground surface at the damage grade $g r d$.

A higher DEI indicates a more significant extent of global ground damage. Because the amount of grade, the involved subsidence factors and the threshold values of the subsidence factors at each grade are different for different criteria (e.g., Table 5 vs. Table 6), the DEI is calculated separately for buildings and timberland in each simulation test; the results are given in Table 7 . It should be noted that this index is not used to assess the damage grade of a specific point; the indexes obtained from different assessing criteria are not comparable.

Table 7. Subsidence areas and global ground damage extent indexes (DEI) of the simulation tests.

\begin{tabular}{cccc}
\hline Test ID & Subsidence Area $\mathbf{( h m}^{\mathbf{2}} \mathbf{)}$ & DEI for Buildings & DEI for Timberland \\
\hline 1 & 83.61 & 2.50 & 1.61 \\
2 & 89.73 & 2.33 & 1.30 \\
3 & 61.29 & 2.21 & 1.24 \\
4 & 81.99 & 1.94 & 1.18 \\
5 & 92.43 & 2.38 & 1.47 \\
6 & 70.83 & 2.09 & 1.07 \\
7 & 76.77 & 2.34 & 1.36 \\
8 & 79.65 & 1.86 & 1.07 \\
9 & 75.87 & 2.30 & 1.26 \\
10 & 90.81 & 2.42 & 1.41 \\
11 & 105.30 & 2.35 & 1.30 \\
12 & 80.10 & 1.74 & 1.00 \\
13 & 66.87 & 1.73 & 1.00 \\
14 & 65.97 & 1.80 & 1.43 \\
15 & 108.63 & 2.45 & 1.00 \\
16 & 53.37 & 1.69 & 1.63 \\
17 & 98.01 & 2.52 & 1.43 \\
18 & 78.39 & 2.44 & 1.58 \\
19 & 67.59 & 2.44 & 1.08 \\
20 & 96.03 & 1.94 & 1.00 \\
21 & 113.31 & 1.67 & 1.36 \\
22 & 75.69 & 2.24 & 1.06 \\
23 & 87.21 & 2.03 & 1.00 \\
24 & 94.05 & 1.73 & 1.30 \\
25 & 63.45 & 2.18 & \\
& & & \\
& & & \\
\end{tabular}

\subsection{Key Parameters of Coalface on Global Ground Damage}

This study uses the ANOVA method to determine which of the four simulative parameters of the coalface affect the ground damage, i.e., to find out the so-called key parameters. This statistics method is used to determine the significances of factors on the research results (the DEI in this case) by analyzing the contributions of variations from different sources to the total variation.

Using the ANOVA functionality of Mathematica and taking the four coalface parameters in Table 2 and the DEI results in Table 7 from all 25 tests into account, the variance analysis tables are 
computed and given as Tables 8 and 9 with respect to the DEI for building and timberland damage assessments, respectively.

Table 8. Variance analysis of the DEI as obtained from the building damage assessment.

\begin{tabular}{ccccccc}
\hline $\begin{array}{c}\text { Source of } \\
\text { Variance }\end{array}$ & DOF & $\begin{array}{c}\text { Sum of } \\
\text { Square }\end{array}$ & $\begin{array}{c}\text { Mean } \\
\text { Square }\end{array}$ & F-Ratio & P-Value & Significant \\
\hline Factor A & 4 & 0.21 & 0.05 & 13.22 & $1.33 \times 10^{-3}$ & Yes \\
Factor B & 4 & 0.03 & $7.28 \times 10^{-3}$ & 1.85 & 0.21 & \\
Factor C & 4 & 1.77 & 0.44 & 112.59 & $4.57 \times 10^{-7}$ & Yes \\
Factor D & 4 & 0.01 & $3.28 \times 10^{-3}$ & 0.83 & 0.54 & \\
Error & 8 & 0.03 & $3.93 \times 10^{-3}$ & & & \\
Total & 24 & 2.05 & & & & \\
\hline
\end{tabular}

Note: Factors A, B, C and D can be found in Table 1.

Table 9. Variance analysis of the DEI as obtained from the timberland damage assessment.

\begin{tabular}{ccccccc}
\hline $\begin{array}{c}\text { Source of } \\
\text { Variance }\end{array}$ & DOF & $\begin{array}{c}\text { Sum of } \\
\text { Square }\end{array}$ & $\begin{array}{c}\text { Mean } \\
\text { Square }\end{array}$ & F-Ratio & P-Value & Significant \\
\hline Factor A & 4 & 0.05 & 0.01 & 5.24 & 0.02 & \\
Factor B & 4 & $5.00 \times 10^{-3}$ & $1.25 \times 10^{-3}$ & 0.57 & 0.69 & Yes \\
Factor C & 4 & 0.99 & 0.25 & 113.07 & $4.50 \times 10^{-7}$ & \\
Factor D & 4 & $8.53 \times 10^{-3}$ & $2.13 \times 10^{-3}$ & 0.98 & 0.47 & \\
Error & 8 & 0.02 & $2.18 \times 10^{-3}$ & & & \\
Total & 24 & 1.06 & & & & \\
\hline
\end{tabular}

Note: Factors A, B, C and D can be found in Table 1.

In ANOVA, the zero hypothesis $H_{0}$ is that the factors (Factors $\mathrm{A}, \mathrm{B}, \mathrm{C}$ and $\mathrm{D}$ ) do not have influence on the DEI; the alternative hypothesis $H_{a}$ is that one or more factors have influence on the DEI; and the significance level $\alpha$ is 0.01 .

Taking the P-Value in Tables 8 and 9 that are less than 0.01 as reliable, the key parameters of the coalface that affect the ground damage (the DEI) are not the same for buildings and timberland.

As illustrated in Table 8, the factor A (length in the dip direction) and factor C (thickness) significantly influence the DEI, i.e., they are the key parameters of the coalface considering buildings on the ground. The relationship from fitting these two factors (the 2nd and 4th columns in Table 2) and the simulated DEI (the 3rd column in Table 7) using the least square method in Mathematica can be described by the following equation:

$$
D E I_{\text {bld }}(A, C)=-1.54 \times 10^{-5}(A-371.17)^{2}-8.98 \times 10^{-3}(C-11.09)^{2}+2.52
$$

where $D E I_{b l d}$ is the DEI obtained from the building damage assessment, $A$ is the length of the coalface in the dip direction (factor $\mathrm{A}$ ) and $C$ is the thickness of the coalface (factor $\mathrm{C}$ ). The DEI with respect to building as obtained by the simulations and the fitting equation are shown in Figure 8a. The parts $-1.54 \times 10^{-5}(A-371.17)^{2}$ and $-8.98 \times 10^{-3}(B-11.09)^{2}$ in Equation (11) are plotted in Figure $8 \mathrm{~b}, \mathrm{c}$, respectively, for better understanding. 


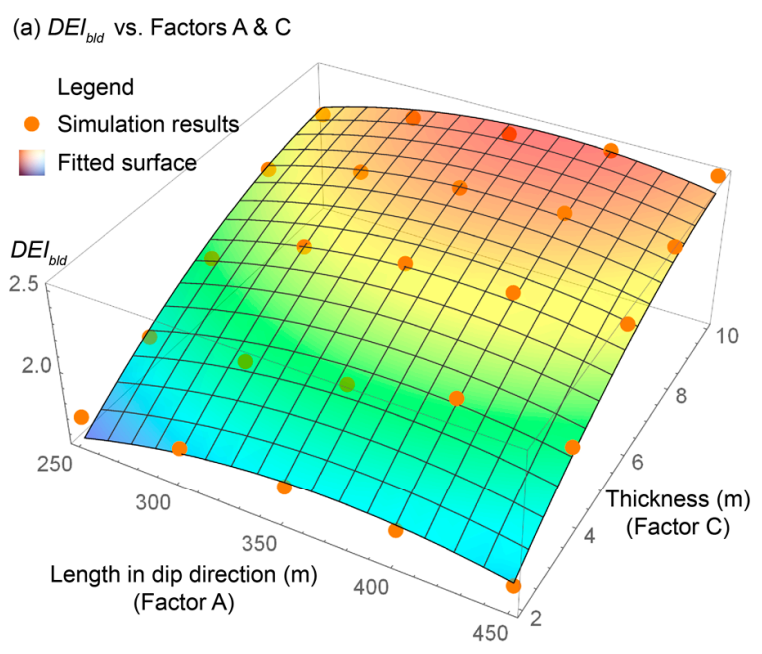

(b) $D E I_{b l d}$ vs. Factor A

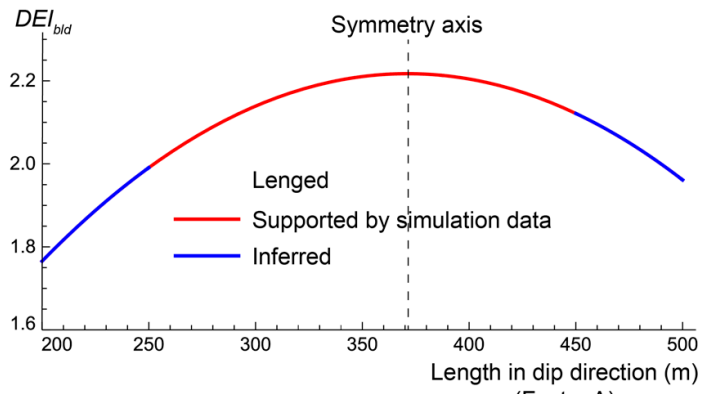

(c) $D E I_{b i d}$ vs. Factor $C$

(Factor A)

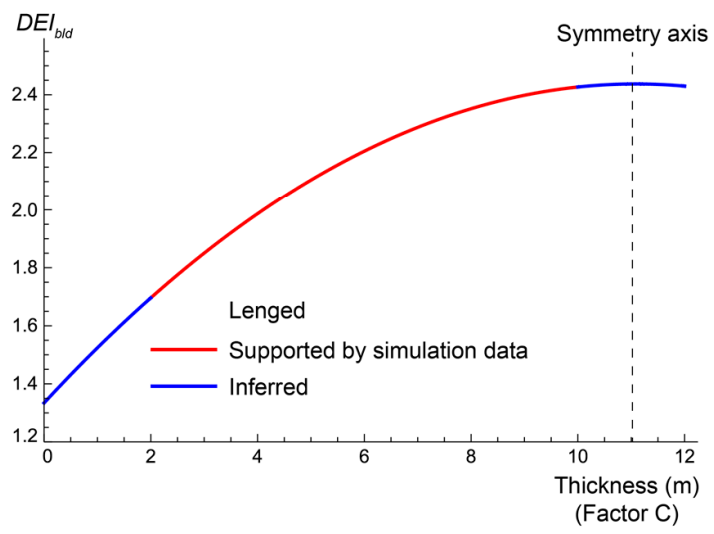

Figure 8. The relationship between the $D E I_{b l d}$ and the length in dip direction (Factor $\mathrm{A}$ ) and thickness (Factor C) of the coalface: (a) DEI $I_{\text {bld }}$ vs. Factors A and C; (b) DEI $I_{\text {bld }}$ vs. Factor A; (c) DEI bld vs. Factor C.

As illustrated in Table 9, the factor C (thickness) significantly influences the index DEI, i.e., it is the key parameter of the coalface considering timberland on the ground. The relationship by fitting this factor (4th column in Table 2) and the simulated DEI (4th column in Table 7) using the least square method in Mathematica can be described by the following equation:

$$
D E I_{t l}(C)=0.83+6.96 \times 10^{-2} \mathrm{C}
$$

where $D E I_{t l}$ is the DEI obtained from the timberland damage assessment and $C$ is the thickness of the coalface (factor C). The DEI with respect to timberland as obtained by the simulations and the fitted equation are shown in Figure 9.

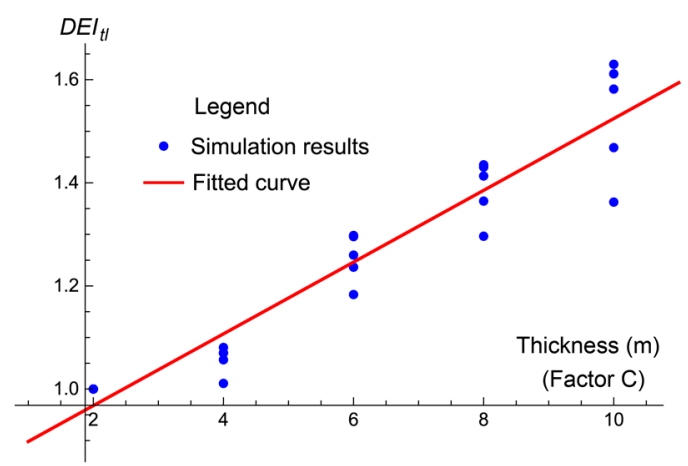

Figure 9. The relationship between the $D E I_{t l}$ and the thickness (Factor C) of the coalface. 


\subsection{Analyses and Discussions}

The damage grade distribution shown in Figure 6 and the results of the variance analysis in Tables 8 and 9 and Figures 8 and 9 based on both the building and timberland damage assessments indicate that:

(1) For different ground objects, the key parameters of the coalface on the ground damage are distinct.

Many studies $[4,7,8,17,19,21,27-29,41,53]$ have discussed the differences of mining-subsidence influences on different surface objects. The sensitive subsidence factors, damage grading method and the damage mechanisms are interested topics.

This paper is more like a reverse study, after the assessment of the ground damage, the assessed results are used to back analysis of the so-called key parameters of the coalface. For buildings, the length in the dip direction and the thickness of the coalface are the key parameters; for timberland, only the thickness of the coalface is the key parameter.

(2) When assessing the building damage, three ground subsidence deformations (slope, curvature and horizontal deformation) are considered. Higher grade damage occurs along the coalface edges.

The influence of the coalface length in the dip direction (factor A) on the extent of global ground damage (the DEI) can be represented by the $-1.54 \times 10^{-5}(A-371.17)^{2}$ in Equation (11), which appears as a quadratic curve, as shown in Figure $8 b$. As the coalface length in the dip direction increases, the DEI increases first before reaching its extreme value at a dip length of $371.17 \mathrm{~m}$ and then decreases. From the simulation experiments, when the length in the dip direction reaches $350 \mathrm{~m}$, the excavation zone is considered to be critical. Therefore, the above rule can be summarized as follows. When the excavation is sub-critical, longer coalface lengths in the dip direction aggravate the global ground damage (increased DEI) due to the increased subsidence deformation. After the excavation becomes critical, longer coalface lengths in the dip direction increase the subsidence range, but the subsidence deformation does not increase (according to general subsidence theories [54]). Therefore, the area with low damage grade(s) enlarges around the center of the subsidence range, which reduces the global damage extent (decreased DEI). In the Shendong coalfield, the mining and geological conditions are simple and favorable to design successive coalfaces in the dip direction to ensure the excavation inevitably becomes critical (or super-critical) after several coalfaces have been mined. The increased coalface length in the dip direction can accelerate the process of sub-critical to super-critical excavation, i.e., it is advantageous for ground protection. The simple conditions in the Shendong coalfield may cause the length in the dip direction of one super-large coalface to reach (or be close to) the demand value of critical excavation, which causes the appearance of an extreme DEI. This case should be avoided, so it is better not to set the dip length of the first mining coalface at around $350 \mathrm{~m}$.

The influence of the coalface thickness (factor $C$ ) on the extent of global ground damage (the DEI) can be represented as the $-8.98 \times 10^{-3}(B-11.09)^{2}$ in Equation (11), which is quadratic and similar to the length in the dip direction, as shown in Figure $8 \mathrm{c}$. The experimental range of the thickness is $2-10 \mathrm{~m}$ and is located at the left side of the curve where it monotonically increases. Therefore, it is determined that as the thickness of the coalface increases, the global ground damage aggravates (increased DEI) due to the increased subsidence deformations. However, when the thickness of the coalface is close to a certain value ( $11.09 \mathrm{~m}$ in this case, which is the peak of the curve), the rate of increase of the DEI slows. As the experimental thickness ranges from 2 to $10 \mathrm{~m}$, the right side of the curve (where the thickness $>11.09 \mathrm{~m}$ ) is not supported by the experimental data and cannot be considered as the influencing characteristics on the DEI. Fortunately, the thickness of coalface in our studied coal mine is not such large, which is also uncommon in other mines.

(3) In the assessment on timberland damage, vertical subsidence and two ground subsidence deformations (slope and horizontal deformation) are considered. Higher grade damage occurs along the edges and around the center of the coalface. 
From Equation (12), the mining thickness and the global ground damage (the DEI) are linearly related. As the coalface thickness increases, the global ground damage aggravates (increased DEI). Comparing the assessment criteria of the buildings and timberland (Tables 5 and 6), it is found that the timberland can bear higher slopes and horizontal deformations than the buildings and also takes vertical subsidence into account. According to the normal subsidence rules, when the excavation zone is horizontal (or with a gentle slope) and becomes critical, the mining thickness and the maximum vertical subsidence have a linear relationship. Therefore, it is speculated that in the damage assessment of timberland, although the slope and horizontal deformation are considered in the assessment criteria, the vertical subsidence is the most sensitive factor.

(4) Although the relationship between the mining speed and the extent of ground damage is not found in this study, it cannot be arbitrarily concluded that they are not related. This gap may be due to the research method and/or the assessment criteria used in this study, which are not sensitive to the mining speed.

(5) The mining damage studies are gaining more attention nowadays. The existing industry criteria $[33,50]$ and some research achievements $[7,28,53]$ are well applied in the damage assessment. These assessment methods intend to evaluate both the damage distribution and extent of the ground as precise as possible, thereby multi assessment indexes are employed. However, in this study, the damage extent is an intermediary to decide the key parameters of the coalface, it must be quantitative and simple. So, the damage index DEI first introduced herein is quite different from the other studies. It is employed to represent the global damage extent of the entire subsidence-influenced area.

\section{Conclusions}

An orthogonal design method was introduced into the numerical simulation experiments to study the ground damage caused by the super-large coalface in the Shendong coalfield.

An index DEI was introduced to assess the extent of global ground damage of an undermined model. It was defined as the ratio of the summation of all the products of the damage area and its relevant damage grade to the total subsidence area (where vertical subsidence $>10 \mathrm{~mm}$ ). A greater DEI signified more intense global damage occurs at the ground surface. The ANOVA method was then employed to determine the key parameters of the coalface that affect the DEI. There are two main achievements in this study.

(1) The key parameter(s) of a coalface on the ground damage

For different ground objects, the key parameters of the coalface and their influences on the DEI were distinct and described as follows.

The DEI for buildings was sensitive to the dip length and thickness of the coalface. As the dip length increased, the DEI (extent of global ground damage) increased when the excavation was sub-critical but decreased after the excavation became critical. As the thickness increased, the DEI increased, but its increase rate slowed and fell to zero (the DEI reached its extreme value) when the thickness reached approximately $11 \mathrm{~m}$.

The DEI for timberland was sensitive to the thickness of the coalface. The relationship between the thickness and the DEI was positive and linear.

The above achievements were obtained from the conditions of our study area. Although the absolute values of the results may have limitations, the rules and trends of the ground damage caused by the excavation of super-large coalfaces may be used as a reference elsewhere.

(2) The Index DEI

The DEI is a new indicator in the research of mining subsidence damage. Compared with the existing damage assessment indexes aiming at assessing the damage extent of the ground points, this index is simpler, more macroscopic and is suitable to be applied in further analyses, e.g., the parameter optimization of the coalface in this paper. It also can be adopted in other studies concerning the global environment of the mining area. 
Author Contributions: Conceptualization, Y.C. and W.X.; Data curation, Y.C.; Formal analysis, X.L.; Methodology, Y.C.; Project administration, W.X.; Software, Y.C.; Writing-original draft, Y.C. and W.Z.; Writing一review \& editing, X.L. and W.X. All authors have read and agreed to the published version of the manuscript.

Funding: The study was supported by the Natural Science Foundation of Shanxi Province, China (Grant No. 201901D111074) and Open Fund of State Key Laboratory of Water Resource Protection and Utilization in Coal Mining (Grant No. SHJT-16-30.16).

Conflicts of Interest: The authors declare no conflict of interest.

\section{References}

1. Gu, D. Water resource and surface ecology protection technology of modern coal mining in China's energy "Golden Triangle". Strateg. Study CAE 2013, 15, 102-107.

2. Yu, J.; Zhu, L.; Xu, G. Safety and high efficiency adaptability evaluation of coal mine intelligent fully-Mechanized mining face. Coal Sci. Technol. 2019, 47, 60-65.

3. Zhang, D.; Fan, G.; Ma, L.; Wang, X. Aquifer protection during longwall mining of shallow coal seams: A case study in the Shendong Coalfield of China. Int. J. Coal Geol. 2011, 86, 190-196. [CrossRef]

4. Wang, X.; Hu, Z.; Hu, Q.; Chen, C. Evolution and self-healing characteristic of land ecological environment due to super-large coalface mining in windy and sandy region. J. China Coal Soc. 2015, 40, 2166-2172.

5. Peng, S.S.; Li, H.; Zhou, Y. Study on Rock Strata Control in Shendong and the Zungars Coalfields; Science Press: Beijing, China, 2015.

6. Li, L.; Wu, K.; Hu, Z.; Xu, Y.; Zhou, D. Analysis of developmental features and causes of the ground cracks induced by oversized working face mining in an aeolian sand area. Environ. Earth Sci. 2017, 76, 135. [CrossRef]

7. Li, Y.; Bian, Z.; Lei, S.; Liu, Y. Land damage evaluation in coal mining area with super-size mining face at western aeolian sandy area. Coal Sci. Technol. 2017, 45, 188-194.

8. Yan, W.; Dai, H.; Chen, J. Surface crack and sand inrush disaster induced by high-strength mining: Example from the Shendong coal field, China. Geosci. J. 2018, 22, 347-357. [CrossRef]

9. Wang, J.; Wang, Z. Stability of main roof structure during the first weighting in shallow high-intensity mining face with thin bedrock. J. Min. Saf. Eng. 2015, 32, 175-181.

10. Peng, Y.; Qi, Q.; Li, H.; Deng, Z. Numerical simulation and analysis on influencing factors of fractured zone height of high-strength underground mining. J. China Coal Soc. 2009, 34, 145-149.

11. Yan, Y.; Dai, H.; Ge, L.; Guo, J.; Alex, H.-M.N.; Li, X. Numerical simulation of dynamic surface deformation based on DInSAR monitoring. Trans. Nonferr. Metals Soc. China 2014, 24, 1248-1254. [CrossRef]

12. Ma, C.; Cheng, X.; Yang, Y.; Zhang, X.; Guo, Z.; Zou, Y. Investigation on Mining Subsidence Based on Multi-Temporal InSAR and Time-Series Analysis of the Small Baseline Subset-Case Study of Working Faces 22201-1/2 in Bu'ertai Mine, Shendong Coalfield, China. Remote Sens. 2016, 8, 951. [CrossRef]

13. Cai, Y.; Xiao, W.; Li, X.; Zhang, W. Determination Study on the Mining Subsidence Parameters of Super-large Working Face in Shendong Coalfield. Met. Mine 2019, 142-147. [CrossRef]

14. Li, P.; Tan, Z.; Yan, L. A Shaft Pillar Mining Subsidence Calculation Using Both Probability Integral Method and Numerical Simulation. CMES Comput. Model. Eng. Sci. 2018, 117, 231-249. [CrossRef]

15. Gong, Y.; Guo, G. A Data-Intensive FLAC (3D) Computation Model: Application of Geospatial Big Data to Predict Mining Induced Subsidence. CMES Comput. Model. Eng. Sci. 2019, 119, 395-408.

16. Cheng, X.; Ma, C.; Kang, J.; Zou, Y. Simulation and time series analysis of mining subsidence by integrating DInSAR and PIM technology. J. China Univ. Min. Technol. 2018, 47, 1141-1148.

17. Liu, H.; He, C.; Deng, K.; Bian, Z.; Fan, H.; Lei, S.; Zhang, A. Analysis of forming mechanism of collapsing ground fissure caused by mining. J. Min. Saf. Eng. 2013, 30, 380-384.

18. Ju, J.; Xu, J. Surface stepped subsidence related to top-coal caving longwall mining of extremely thick coal seam under shallow cover. Int. J. Rock Mech. Min. Sci. 2015, 78, 27-35. [CrossRef]

19. Hu, Z.; Wang, X.; He, A. Distribution characteristic and development rules of ground fissures due to coal mining in windy and sandy region. J. China Coal Soc. 2014, 39, 11-18.

20. Yang, Z. Prediction of surface subsidence in underground mining seam based on the boundary value method. Rock Soil Mech. 2010, 31, 232-236. 
21. Wang, L.; Wei, S.; Wang, Q. Effect of coal exploitation on ground water and vegetation In the Yushenfu Coal Mine. J. China Coal Soc. 2008, 33, 1408-1414.

22. Li, S.; Bi, Y.; Chen, P.; Zhakypbek, Y.; Liu, S. Effects of AMF cooperating with exogenous calcium on maize growth and soil improvement. Trans. Chin. Soc. Agric. Eng. 2013, 29, 109-116.

23. Lv, X.; Xiao, W.; Zhao, Y.; Zhang, W.; Li, S.; Sun, H. Drivers of spatio-temporal ecological vulnerability in an arid, coal mining region in Western China. Ecol. Indic. 2019, 106, 105475. [CrossRef]

24. Xiao, W.; Lv, X.; Zhao, Y.; Sun, H.; Li, J. Ecological resilience assessment of an arid coal mining area using index of entropy and linear weighted analysis: A case study of Shendong Coalfield, China. Ecol. Indic. 2020, 109, 105843. [CrossRef]

25. Hu, Z.; Chen, C.; Xiao, W.; Wang, X.; Gao, M. Surface movement and deformation characteristics due to high-intensive coal mining in the windy and sandy region. Int. J. Coal Sci. Technol. 2016, 3, 339-348. [CrossRef]

26. Wang, Z.; Bi, Y.; Bin, J.; Zhakypbek, Y.; Peng, S.; Liu, W.; Hao, L. Arbuscular mycorrhizal fungi enhance soil carbon sequestration in the coalfields, northwest China. Sci. Rep. 2016, 6, 34336. [CrossRef]

27. Hu, Z.; Long, J.; Wang, X. Self-healing, natural restoration and artificial restoration of ecological environment for coal mining. J. China Coal Soc. 2014, 39, 1751-1757.

28. Zhao, Y.; Huang, Q.; Xue, J.; Peng, H. Study on the Assessment of Land Destroy Degree in Mine Land Reclamation Design. Met. Mine 2009, 161-163.

29. Zhang, J.; Li, Q.; Hu, Z.; Wang, Y.; Li, Q. Study on Ecological Restoration Mode of Ultra Wide Fully-Mechanized Coal Mining in West China Aeolian Sand Area. Coal Sci. Technol. 2013, 41, 173-177.

30. Saeidi, A.; Verdel, T.; Deck, O. Development of building vulnerability functions in subsidence regions from analytical methods. Géotechnique 2012, 62, 107-120. [CrossRef]

31. Cai, Y.; Verdel, T.; Deck, O. Using plane frame structural models to assess building damage at a large scale in a mining subsidence area. Eur. J. Environ. Civil Eng. 2020, 24, 283-306. [CrossRef]

32. National Coal Board. Subsidence Engineers' Handbook; National Coal Board: London, UK, 1975.

33. State Administration of Work Safety; State Administration of Coal Mine Safety; National Energy Administration; National Railway Administration. The Regulations of Coal Mining and Pillar Design for Protecting Buildings, Water Bodies, Railways, Main Mineshafts and Tunnels; Coal Industry Press: Beijing, China, 2017.

34. Skempton, A.W.; MacDonald, D.H. The allowable settlements of buildings. ICE Proc. Eng. Div. 1956, 5, 727-768. [CrossRef]

35. Papadrakakis, M.; Apostolopoulou, C.; Zacharopoulos, A.; Bitzarakis, S. Three-Dimensional Simulation of Structural Pounding during Earthquakes. J. Eng. Mech. 1996, 122, 423-431. [CrossRef]

36. Domede, N.; Sellier, A.; Stablon, T. Structural analysis of a multi-span railway masonry bridge combining in situ observations, laboratory tests and damage modelling. Eng. Struct. 2013, 56, 837-849. [CrossRef]

37. Abdallah, M.; Verdel, T.; Deck, O. Vulnerability of masonry buildings to mining subsidence studied trough experimental design. In Proceedings of the Post-Mining 2008, Nancy, France, 6-8 February 2008; pp. 1-12.

38. Burland, J.B. Assessment of Risk of Damage to Buildings Due to Tunnelling and Excavation; Imperial College of Science, Technology and Medicine: London, UK, 1995.

39. Boscardin, M.D.; Cording, E.J. Building response to excavation-induced settlement. J. Geotech. Eng. 1989, 115, 1-21. [CrossRef]

40. Finno, R.; Voss, F.; Rossow, E.; Blackburn, J. Evaluating Damage Potential in Buildings Affected by Excavations. J. Geotech. Geoenviron. Eng. 2005, 131, 1199-1210. [CrossRef]

41. Darmody, R.G.; Bauer, R.; Barkley, D.; Clarke, S.; Hamilton, D. Agricultural impacts of longwall mine subsidence: The experience in Illinois, USA and Queensland, Australia. Int. J. Coal Sci. Technol. 2014, 1, 207-212. [CrossRef]

42. Chugh, Y.P. Concurrent mining and reclamation for underground coal mining subsidence impacts in China. Int. J. Coal Sci. Technol. 2018, 5, 18-35. [CrossRef]

43. Yonk, R.M.; Smith, J.T.; Wardle, A.R. Exploring the Policy Implications of the Surface Mining Control and Reclamation Act. Resources 2019, 8, 25. [CrossRef]

44. Yuan, Y.; Zhao, Z.; Zhang, P.; Chen, L.; Hu, T.; Niu, S.; Bai, Z. Soil organic carbon and nitrogen pools in reclaimed mine soils under forest and cropland ecosystems in the Loess Plateau, China. Ecol. Eng. 2017, 102, 137-144. [CrossRef] 
45. Goodman, R.E. Introduction to Rock Mechanics, 2nd ed.; John Wiley \& Sons: New York, NY, USA, 1989.

46. Li, N.; Wang, E.; Ge, M.; Liu, J. The fracture mechanism and acoustic emission analysis of hard roof: A physical modeling study. Arab. J. Geosci. 2015, 8, 1895-1902. [CrossRef]

47. Yang, Y.; Zhang, D.; Bai, X.; Yang, H. Research on Correlation Between Abutment Pressure and Gas Drainage Flow of Coal Seam. Geotech. Geol. Eng. 2018, 36, 2087-2095. [CrossRef]

48. Cai, Y.; Verdel, T.; Deck, O. On the topography influence on subsidence due to horizontal underground mining using the influence function method. Comput. Geotech. 2014, 61, 328-340. [CrossRef]

49. Li, H.; Zhao, B.; Guo, G.; Zha, J.; Bi, J. The influence of an abandoned goaf on surface subsidence in an adjacent working coal face: A prediction method. Bull. Eng. Geol. Environ. 2018, 77, 305-315. [CrossRef]

50. Ministry of Land and Resources of the People's Republic of China. Regulation on Compiling Land Reclamation plan_Part 3: Underground Coalmine (TD/T 1031.3-2011); Standards Press of China: Beijing, China, 2011.

51. Dai, H.; Lian, X.; Liu, J.; Liu, Y.; Zhou, Y.; Deng, W.; Cai, Y. Model study of deformation induced by fully mechanized caving below a thick loess layer. Int. J. Rock Mech. Min. Sci. 2010, 47, 1027-1033. [CrossRef]

52. Chen, C. Dynamic Deformation Characteristics and Its Self-healing of Surface and Overburden Due to Super-Large Working Face in Windy and Sandy Region; China University of Mining and Technology (Beijing): Beijing, China, 2018.

53. Kundu, N.K.; Ghose, M.K. Studies on the Topsoil of an Underground Coal-mining Project. Environ. Conserv. 1994, 21, 126-132. [CrossRef]

54. Dai, H.; Wang, J. Prediction model for surface movement and deformation induced by sub-critical extraction. J. China Coal Soc. 2004, 28, 583-587.

(C) 2020 by the authors. Licensee MDPI, Basel, Switzerland. This article is an open access article distributed under the terms and conditions of the Creative Commons Attribution (CC BY) license (http://creativecommons.org/licenses/by/4.0/). 